\title{
Validation of modified forms of the PedsQL generic core scales and cancer module scales for adolescents and young adults (AYA) with cancer or a blood disorder
}

\author{
Jane E. Ewing - Madeleine T. King • \\ Narelle F. Smith
}

Accepted: 17 November 2008/Published online: 23 January 2009

(C) The Author(s) 2009. This article is published with open access at Springerlink.com

\begin{abstract}
Purpose To validate two health-related quality of life (HRQOL) measures, the PedsQL Generic Core and Cancer Module adolescent forms (13-18 years), after modification for 16-25-year-old adolescents and young adults (AYA) with cancer or a blood disorder.

Methods AYA patients and nominated proxies were recruited from three Sydney hospitals. Modified forms were administered by telephone or in clinics/wards. Analyses included correlations, factor analysis, and analysis of variance of known-groups (defined by the Memorial Symptom Assessment Scale).

Results Eighty-eight patients and 79 proxies completed questionnaires. Factor structures consistent with those of the unmodified forms confirmed construct validity. Cronbach's alpha ranged 0.81-0.98. Inter-scale correlations were as hypothesized, confirming discriminant validity. Statistically significant differences between groups with mild, moderate, and severe symptoms $(P<0.05)$ confirmed clinical validity.
\end{abstract}

J. E. Ewing $(\bowtie) \cdot$ N. F. Smith

Department of Mathematical Sciences, Faculty of Science,

University of Technology, Sydney (UTS), P.O. Box 123,

Broadway, Sydney, NSW, Australia

e-mail: jane.ewing@uts.edu.au

M. T. King

Quality of Life Office, Psycho-Oncology Cooperative Research

Group, University of Sydney, Sydney, Australia

M. T. King

Centre for Health Economics Research \& Evaluation, University of Technology Sydney (UTS), P.O. Box 123, Broadway, Sydney, NSW, Australia
Conclusion These modified forms provide reliable and valid measures of HRQOL in AYA with cancer or a blood disorder, suitable for clinical trials, research, and practice.

Keywords Quality of life - Adolescents · Validation studies · Cancer · Blood disorder · Proxy

\section{Introduction}

Disease and treatment affect many aspects of the quality of people's lives-not only physical aspects but also social and emotional aspects. The diseases themselves can cause symptoms such as fatigue and pain. Common treatments such as chemotherapy, radiotherapy, and surgery, whether palliative or curative, can have deleterious side-effects as well as beneficial effects [1,2]. The importance of these issues, not only to patients but also to their families, carers, and clinicians, has led to the development of instruments designed to measure the impact of a range of diseases and treatments by self-report. These instruments are commonly called health-related quality of life (HRQOL) measures. There are a large number and wide array of HRQOL instruments, and a comprehensive methodology for testing their reliability, validity, responsiveness, and interpretability [3].

Adolescents and young adults (AYA) with cancer and blood disorders are an obvious case for HRQOL assessment because they lack an appropriate model of care [4] and the range of implications for them is very different from that for adults and younger children. Furthermore, AYA percentage improvement in survival lags behind all other age-groups [1, 5-7]. AYA may experience interruptions in physical growth, pubertal development, psychosocial and cognitive development [3, 7], and to their education, employment, 
and independence $[1,7,8]$. In relation to cancer, there are numerous instruments to measure HRQOL, such as the modular approaches of both the EORTC [9] and the FACT$\mathrm{G}[3,10]$, but few for those with blood disorders. Most HRQOL instruments are designed for adults and some for paediatric patients. Adult questionnaires are inappropriate for paediatric patients because of their reading and comprehension levels, whereas AYA, being between childhood and adulthood, have different developmental needs, issues, and concerns [1, 7]. Little is known about the patient's satisfaction, preferences for services, impact of illness, and HRQOL as few validated AYA instruments are available that address their developmental needs.

Common treatments for blood disorders may include chelation and blood transfusions. The chronic and serious nature of these diseases and treatments further heightens the special needs of AYA $[1,7,11,12]$. Despite this, too few are included in clinical trials $[1,7,13]$. With increasing international recognition of the inadequacy of AYA care, the European Journal of Cancer dedicated the 18th issue of the 39th volume 2003 to this age-group.

The Pediatric Quality of Life Inventory (PedsQL) is a suite of instruments designed to measure HRQOL in children, and in adolescents aged 13-18 years [14-16] using a 30 -day recall period. The approach is modular, with generic core scales complemented by disease-specific modules, such as the PedsQL Cancer Module. The validity and reliability of the PedsQL has been demonstrated in various paediatric populations e.g. cancer [17], diabetes [18], and heart disease [19]. There are parallel child self-report and parent proxy-report formats, and age-specific forms differing in developmentally appropriate language for ages 2-4 years (toddler, proxy-report only), 5-7 years (young child), 8-12 years (child), and 13-18 years (adolescent) [14-16, 20].

The aim of this study was to modify the existing adolescent forms of the PedsQL 4.0 Generic Core Scales and PedsQL 3.0 Cancer Module appropriate to AYA aged 16-25 years with cancer or a blood disorder, and evaluate the reliability and validity of these modified forms.

\section{Methods}

Participants, recruitment and consent

AYA inclusion criteria were: aged $16-32$ years old and diagnosed with cancer or a blood disorder at least three months prior to recruitment (to allow participants time to adjust to their diagnosis and treatment). AYA exclusion criteria were: inability to read and write English; co-morbidity; major developmental disorder; receiving end-of-life care; recently diagnosed; or involved in a concurrent "late effects" study. Proxies were also recruited; the only proxy exclusion criterion was lack of English literacy. Recruitment occurred from 1st July 2003 to 31st May 2004 via three Sydney hospitals: Sydney Children's Hospital, Prince of Wales Hospital, and Royal Hospital for Women. Eligible AYA participants were identified from databases or patient records by a member of the medical team in liaison with the hospital research scientist, database managers, or clinical nurse consultant. Permission was sought from the treating clinician to approach eligible patients. Most AYA participants were recruited by phone after receiving an introductory letter from their treating clinician; some were recruited on wards or at out-patient clinics. All participants provided informed, written consent, and could withdraw at any time. Permission was gained from AYA participants to approach their nominated proxy/caregiver. If the nominated proxy was absent, and the young adult patient agreed, the proxy was contacted and recruited, usually by phone and post.

The study was approved by the Scientific Review Committees of the South Eastern Sydney Area Health Service and Royal Hospital for Women, and the University of Technology Sydney Human Ethics Research Committee.

\section{The PedsQL instruments}

The PedsQL 4.0 Generic Core Scales and PedsQL 3.0 Cancer Module adolescent forms were used after minor modification in wording for AYA (described below). The generic core scales contain 23 items grouped into four scales-Physical Health Summary Score (eight items), Emotional (five items), Social (five items), and School (five items) - plus composite scales for a Total Scale Score (23 items) and a Psychosocial Health Summary Score (the sum of Emotional, Social, and Study/Work functioning, 15 items). The cancer module contains 27 items, grouped into eight scales-Pain and Hurt (two items); Nausea (five items); Procedural Anxiety (three items); Treatment Anxiety (three items); Worry (three items); Cognitive Problems (five items); Perceived Physical Appearance (three items); and Communication (three items) [14-20].

\section{Modifications to PedsQL instruments for AYA}

The existing adolescent report (ages 13-18 years) and associated parent report of the Generic Core Scales and the Cancer Module were used as the basis for the corresponding AYA forms. The modifications were based on feedback from two focus groups conducted by the first author (JE) in Auckland, New Zealand, in 1999; one group comprised a dozen AYA patients and family members, the other comprised eight health and allied health professionals, including nurses, doctors, and social workers who 
Table 1 Modifications to the existing adolescent report and associated parent report of the PedsQL Generic Core Scales (GC) and PedsQL Cancer Module (CM) to create the adolescent and young adult (AYA) self-report and associated proxy-report forms

\begin{tabular}{lll}
\hline $\begin{array}{l}\text { Adolescent } \\
\text { form }\end{array}$ & Adolescent and young adult form & Instrument, domain and item numbers \\
\hline Ages 13-18 & Ages 16-24 (incl.) & GC and CM-instrument front page \\
Teen or teens & Young person or young people or young adult(s) & GC and CM-instrument front page; social functioning: items 1-5 \\
School & Study/work or study & GC, work/study functioning, items 4 and 5; GC, cognitive problems, item 3 \\
Class & Class/at work & GC, work/study functioning, item 1 \\
Schoolwork & Study/work duties & GC, work/study functioning, item 3 \\
Child & Child/charge & GC and CM (proxy-report only) \\
\hline
\end{tabular}

cared for AYA patients. The instruments' principal developer and copyright holder, Professor James Varni, approved the proposed wording modifications (Table 1). The most substantial change was to the school functioning scale of the Generic Core Scales, in which references to school were rephrased to reflect this mildly older age group's engagement in combinations of study and work.

The Generic Core Scales and the Cancer Module have the same item stem and response options, and are as in the adolescent forms. The item stem in the AYA forms asks: "In the past one month, how much of a problem has this been for you". In the corresponding proxy forms, it asks: "In the past month, how much of a problem has your charge/child had with..." and the item descriptions are written in the third person rather than the first person. The response options are the same for both AYA and proxy forms: $0=$ never; $1=$ almost never; 2 = sometimes; $3=$ often; $4=$ almost always.

\section{Memorial symptom assessment scale (MSAS)}

We tested the clinical validity of the HRQOL measures [21] against the memorial symptom assessment scale (MSAS) $[22,23]$, an external criterion, rather than use the more general divisions used by Varni et al. in earlier work (ontreatment in the past 12 months versus off-treatment for more than 12 months [14, 20] and chronically ill versus acutely ill and healthy populations of young people [15]). The MSAS [22, 23] is a previously validated 30-item patient-rated instrument which provides multidimensional information about the symptoms experienced by people with cancer in the past week. It was used to categorise AYA participants into three known groups based on the tertiles of the sample's MSAS-PHYS scores: Mild (0-0.19), Moderate (0.20-0.99), and Severe (1.0-4.0) Symptoms.

\section{Data collection}

AYA participants were given or posted a booklet containing a set of questionnaires, in this order: PedsQL Generic Core Scales; PedsQL Cancer Module; AYA satisfaction survey; preferences survey; MSAS (for AYA only); global impact survey; and questions about their current disease, treatment, and socio-demographics. Each proxy participant was nominated by the AYA patient and were given or posted a booklet containing parallel versions of the AYA questionnaires. All participants were encouraged to follow the PedsQL administration guidelines [14].

\section{Instrument scoring}

The PedsQL scales were scored according to Varni's standard algorithm [14]. Each domain score was the unweighted sum of the item scores, linearly transformed to a 0-100 scale range on which a higher score represented better quality of life. If less than $50 \%$ of the items in a scale were missing, the missing item values were imputed as the mean of the completed items within that scale [24]; otherwise the scale score was recorded as missing [3, 25, 26]. This method is considered the least biassed procedure for missing data, although it may artificially reduce variability [15, 24]. The MSAS scoring, including missing values, was as recommended elsewhere [22, 23].

\section{Validation analyses}

Several aspects of construct validity were investigated. Confirmatory factor analysis [3, 14] was used to determine whether the modified items correlated within domains in the same way as reported by Varni et al. [14]. Internal consistency reliability was summarised with Cronbach's alpha coefficient [14, 27, 28]. Correlation matrices (Pearson's and Kendall's Tau b correlation coefficients) were used to examine the degree and pattern of correlation among multi-item scales. In this context, correlations in the range $0.1-0.29$ were considered a small effect; those in the range $0.3-0.49$ were considered moderate and those greater than 0.5 were considered large [29]. Known-groups analysis was used to test the clinical validity of the new AYA forms [21]. The MSAS [22, 23] provided an external criterion to categorise patients into three groups identified by AYA scores on the MSAS-PHYS scale where symptom 
Table 2 Clinical and sociodemographic profile of the sample $(\%)$ a All items are reported by the AYA and their nominated Proxy

b $17 \%$ of AYA had a combination of 2 or 3 different types of treatment in the past month, e.g., surgery, chemotherapy and a transfusion. Hence Treatments add to > $100 \%$ due to duplications

c Missing data: Proxy age 10\%, Proxy marital status $10 \%$, Educational status: AYA 2\% and proxy $10 \%$

\begin{tabular}{|c|c|c|c|}
\hline Characteristics $^{\mathrm{a}}$ & & $\begin{array}{l}\text { Adolescent and young } \\
\text { adults }(n=88)\end{array}$ & $\begin{array}{l}\text { Nominated } \\
\text { proxies }(n=79)\end{array}$ \\
\hline \multirow[t]{2}{*}{ Illness } & Cancer & 74 & \\
\hline & Blood disorder & 26 & \\
\hline \multirow[t]{4}{*}{ Current status } & Ongoing/in relapse & 32 & \\
\hline & Off-treatment: & & \\
\hline & In remission & 48 & \\
\hline & Cured/long-term follow-up & 20 & \\
\hline \multirow{7}{*}{$\begin{array}{l}\text { Treatments over } \\
\text { past month }^{\mathrm{b}}\end{array}$} & Chemotherapy & 13 & \\
\hline & Radiation & 3 & \\
\hline & Surgery & 5 & \\
\hline & Transplant & 1 & \\
\hline & Transfusion & 18 & \\
\hline & Chelation & 10 & \\
\hline & No treatment & 68 & \\
\hline \multirow[t]{2}{*}{ Age brackets—AYA } & 16-19 years & 54 & \\
\hline & $20-25$ years & 46 & \\
\hline \multirow[t]{5}{*}{ Age brackets-proxy ${ }^{\mathrm{c}}$} & 20-29 years & & 5 \\
\hline & 30-39 years & & 10 \\
\hline & 40-49 years & & 52 \\
\hline & $50-59$ years & & 21 \\
\hline & $60+$ & & 2 \\
\hline \multirow[t]{2}{*}{ Ethnic group } & European descent & 77 & 81 \\
\hline & Other & 23 & 19 \\
\hline Gender & Female & 58 & 76 \\
\hline \multirow[t]{5}{*}{ Marital status ${ }^{\mathrm{c}}$} & Single & 81 & 2 \\
\hline & Married & 10 & 72 \\
\hline & Separated/divorced & 1 & 9 \\
\hline & Defacto & 8 & 6 \\
\hline & Widowed & - & 1 \\
\hline \multirow[t]{5}{*}{ Educational status ${ }^{\mathrm{c}}$} & 9th Grade or less & 3 & 10 \\
\hline & 9th-12th Grade & 49 & 21 \\
\hline & High school certificate & 17 & 16 \\
\hline & Tertiary cert course & 15 & 23 \\
\hline & Graduate or prof degree & 14 & 21 \\
\hline
\end{tabular}

severity cut-off points were determined as: Mild (MSASPHYS = 0-0.19), Moderate (MSAS-PHYS = 0.20-0.99), Severe Symptom (MSAS-PHYS $=1-\max$ ). The mean HRQOL scores of these groups were compared to see whether they conformed to patterns predicted by clinical knowledge of this external criterion. Thus patients who reported severe symptom experience were expected to have worse HRQOL in all domains than those who reported moderate symptom experience, and this intermediate group was expected to have worse HRQOL in all domains than those who reported mild symptom experience. These hypotheses were tested with ANOVA for the Generic Core and pair-wise $P$-values were calculated using Tukey's HSD post-hoc test. However, because distributions for some of the scores from the Cancer Module did not meet normality requirements, the Kruskal-Wallis (K-W) non-parametric test was used to test differences between symptom groups and the MannWhitney $U$-test was used to determine significance between pairs of groups within domains.

The degree of agreement between AYA self-report and proxy report was tested with intraclass correlations, and the degree of proxy bias was assessed by testing the mean difference between self-report and proxy-report scores with a Mann-Whitney $U$-test. All analyses were conducted with the Statistical Package for Social Scientists (SPSS) for Windows and all tests of significance were two-sided at the 95\% confidence level. 


\section{Results}

Eighty-eight AYA participants and 79 nominated proxy/ caregivers were recruited. Ten people declined participation: two patient-proxy dyads, three AYA patients (who declined but were happy for their proxies to participate), and a further three proxies. Some AYA did not wish to nominate a proxy. Most AYA participants were recruited by phone and completed their questionnaires at home ( $n=68,78 \%)$. The remainder were recruited at out-patient clinics $(n=16)$ or as hospital in-patients $(n=4)$, and completed their questionnaires in a clinic or ward. Most proxies completed their questionnaires at home, $86 \%$ were parents and 7\% were partners of AYA. Of the 167 completed questionnaires, few items were missed: the percentage of missed items for the generic instrument for AYA and proxy-reports was $0 \%$ and $0.1 \%$, respectively. The response rate for the Cancer Module was similar to that for the Generic Core.

Table 2 shows the clinical and demographic characteristics of the AYA and their proxies. Cancer diagnoses included leukaemia, Hodgkin's lymphoma, non-Hodgkin's lymphoma, Ewing's sarcoma, Wilm's tumour, neuroblastoma, carcinoma, and osteosarcoma. Of the 23 young

Table 3 Adolescent and young adult (AYA) self-report of their quality of life using the AYA modified PedsQL Generic Core Scales and Cancer Module $^{\mathrm{a}}$ : mean (SD) and Cronbach's alpha ${ }^{\mathrm{b}}(\alpha)$ for the sample as a whole, and ceiling and floor effects ${ }^{\mathrm{c}}$ for each of the three known groups ${ }^{\mathrm{d}}$

\begin{tabular}{|l|c|c|c|c|c|c|c|c|c|}
\hline \multicolumn{2}{|c|}{ Self-Report } & \multicolumn{2}{c|}{$\begin{array}{c}\text { Overall } \\
\mathrm{n}=88\end{array}$} & \multicolumn{2}{c|}{$\begin{array}{c}\text { Mild Symptoms } \\
\mathrm{n}=37\end{array}$} & \multicolumn{2}{c|}{$\begin{array}{c}\text { Moderate Symptoms } \\
\mathrm{n}=39\end{array}$} & \multicolumn{2}{c|}{$\begin{array}{c}\text { Severe Symptoms } \\
\mathrm{n}=12\end{array}$} \\
\hline \multicolumn{1}{|c|}{ Generic Core } & $\begin{array}{l}\text { No. } \\
\text { items }\end{array}$ & $\begin{array}{l}\text { Mean } \\
\text { (SD) }\end{array}$ & $\alpha^{\mathrm{b}}$ & \%Floor & \%Ceiling & \%Floor & \%Ceiling & \%Floor & \%Ceiling \\
\hline Total Score & 23 & $76(19)$ & .95 & 0 & 11 & 0 & 0 & 0 & 0 \\
\hline Physical Health & 8 & $75(25)$ & .93 & 0 & 41 & 0 & 10 & 0 & 0 \\
\hline Psychosocial Health & 15 & $76(17)$ & .92 & 0 & 14 & 0 & 0 & 0 & 0 \\
\hline $\begin{array}{l}\text { Emotional } \\
\text { Functioning }\end{array}$ & 5 & $73(20)$ & .86 & 0 & 32 & 0 & 5 & 0 & 0 \\
\hline Social Functioning & 5 & $88(15)$ & .81 & 0 & 68 & 0 & 31 & 0 & 8 \\
\hline $\begin{array}{l}\text { Study/Work } \\
\text { Functioning }\end{array}$ & 5 & $69(26)$ & .88 & 0 & 27 & 0 & 0 & 0 & 0 \\
\hline
\end{tabular}

Cancer Module

\begin{tabular}{|l|c|l|c|c|c|c|c|c|c|}
\hline Pain \& Hurt & 2 & $75(24)$ & .75 & 0 & 60 & 0 & 21 & 0 & 0 \\
\hline Nausea & 5 & $84(21)$ & .89 & 0 & 62 & 0 & 31 & 0 & 0 \\
\hline Procedural Anxiety & 3 & $80(29)$ & .85 & 0 & 70 & 5 & 39 & 17 & 17 \\
\hline Treatment Anxiety & 3 & $80(28)$ & .83 & 0 & 70 & 8 & 33 & 0 & 25 \\
\hline Worry & 3 & $69(23)$ & .76 & 0 & 24 & 0 & 0 & 0 & 8 \\
\hline Cognitive Problems & 5 & $73(25)$ & .90 & 0 & 46 & 0 & 13 & 0 & 17 \\
\hline $\begin{array}{l}\text { Perceived } \\
\text { Appearance }\end{array}$ & 3 & $73(25)$ & .77 & 0 & 43 & 0 & 18 & 0 & 17 \\
\hline Communication & 3 & $78(24)$ & .76 & 0 & 65 & 3 & 18 & 0 & 8 \\
\hline
\end{tabular}

a The PedsQL Generic Core Scales and the PedsQL Cancer Module has a 1-month recall interval

b Internal consistency reliability coefficient, Cronbach's alpha $(\alpha)$

c $\%$ Floor and $\%$ Ceiling are the percentage of scores at the extreme values of the scale range

d Known groups determined by AYA scores on the MSAS-PHYS: Mild symptoms (MSAS-PHYS = 0-0.19), Moderate (MSAS-PHYS = 0.200.99), and Severe Symptom (MSAS-PHYS = 1-max) 
Table 4 Proxy-report of adolescent and young adult (AYA) quality of life using the AYA modified PedsQL Generic Core Scales and PedsQL Cancer Module ${ }^{\mathrm{a}}$ : mean (SD) and Cronbach's alpha ${ }^{\mathrm{b}}(\alpha)$ for the sample as a whole, and ceiling and floor effects ${ }^{\mathrm{c}}$ in each of the three known groups ${ }^{\mathrm{d}}$

\begin{tabular}{|l|c|c|c|c|c|c|c|c|c|}
\hline \multicolumn{2}{|c|}{ Proxy-Report $^{\mathrm{e}}$} & \multicolumn{2}{c|}{$\begin{array}{c}\text { Overall } \\
\mathrm{n}=79\end{array}$} & \multicolumn{2}{c|}{$\begin{array}{r}\text { Mild Symptoms } \\
(1) \mathrm{n}=35\end{array}$} & $\begin{array}{r}\text { Moderate Symptoms } \\
(2) \mathrm{n}=34\end{array}$ & \multicolumn{2}{c|}{$\begin{array}{c}\text { Severe Symptoms } \\
(3)\end{array}$} \\
\hline \multicolumn{1}{|c|}{ Generic Core } & $\begin{array}{c}\text { No. of } \\
\text { items }\end{array}$ & $\begin{array}{c}\text { Mean } \\
(\mathrm{SD})\end{array}$ & $\boldsymbol{\alpha}^{\mathbf{b}}$ & \%Floor & \%Ceiling & \%Floor & \%Ceiling & \%Floor & \%Ceiling \\
\hline Total Score & 23 & $74(21)$ & .96 & 0 & 23 & 0 & 3 & 0 & 0 \\
\hline Physical Health & 8 & $75(26)$ & .93 & 0 & 37 & 0 & 15 & 0 & 0 \\
\hline $\begin{array}{l}\text { Psychosocial } \\
\text { Health }\end{array}$ & 15 & $74(21)$ & .94 & 0 & 29 & 0 & 3 & 0 & 0 \\
\hline $\begin{array}{l}\text { Emotional } \\
\text { Functioning }\end{array}$ & 5 & $69(26)$ & .91 & 0 & 40 & 0 & 12 & 0 & 0 \\
\hline Social Functioning & 5 & $85(18)$ & .85 & 0 & 60 & 0 & 41 & 0 & 10 \\
\hline $\begin{array}{l}\text { Study/Work } \\
\text { Functioning }\end{array}$ & 5 & $69(27)$ & .89 & 0 & 40 & 0 & 12 & 0 & 0 \\
\hline
\end{tabular}

Cancer Module

\begin{tabular}{|l|c|c|c|c|c|c|c|c|c|}
\hline Pain \& Hurt & 2 & $75(25)$ & .85 & 0 & 54 & 0 & 29 & 0 & 10 \\
\hline Nausea & 5 & $83(25)$ & .95 & 0 & 77 & 0 & 47 & 10 & 0 \\
\hline Procedural Anxiety & 3 & $81(28)$ & .98 & 0 & 74 & 6 & 53 & 10 & 10 \\
\hline Treatment Anxiety & 3 & $77(27)$ & .94 & 3 & 66 & 3 & 29 & 0 & 20 \\
\hline Worry & 3 & $68(27)$ & .91 & 0 & 34 & 0 & 18 & 10 & 0 \\
\hline $\begin{array}{l}\text { Cognitive } \\
\text { Problems }\end{array}$ & 5 & $76(27)$ & .93 & 0 & 54 & 3 & 32 & 0 & 10 \\
\hline $\begin{array}{l}\text { Perceived } \\
\text { Appearance }\end{array}$ & 3 & $74(26)$ & .83 & 0 & 49 & 3 & 24 & 10 & 10 \\
\hline Communication & 3 & $77(26)$ & .89 & 0 & 51 & 3 & 35 & 10 & 30 \\
\hline
\end{tabular}

a The PedsQL Generic Core Scales and the PedsQL Cancer Module has a 1-month recall interval

b Internal consistency reliability coefficient, Cronbach's alpha $(\alpha)$

c $\%$ Floor and $\%$ Ceiling are the percentage of scores at the extreme values of the scale range

d Known groups determined by AYA scores on the MSAS-PHYS: Mild symptoms (MSAS-PHYS $=0-0.19$ ), Moderate (MSAS-PHYS $=0.20$ 0.99 ), and Severe Symptom (MSAS-PHYS = 1-max)

e Each proxy is as nominated by the AYA patient

adults with a blood disorder, 13 had thalassemia and ten had other blood disorders such as sickle cell anemia, Von Willebrand's disease, anemia, and haemophilia. The AYA age distribution was bimodal (at 17 and 22 years); 54\% were 16-19 years and 46\% were 20-25 years with two outliers $(26,32$ years). There were no more than $10 \%$ missing data, and $17 \%$ of AYA had a combination of two or three different types of treatment in the past month, e.g. surgery, chemotherapy, and a transfusion. Hence treatments add to more than $100 \%$ because of duplication.

Of the 88 AYA participants, 37 reported mild to no symptoms, 39 reported moderate symptoms, and 12 
Table 5 Adolescent and young adult (AYA) self-report by Symptom Severity Group using the AYA modified PedsQL Generic Core Scales and Cancer Module domain scores $(n=88)$

\begin{tabular}{|c|c|c|c|c|c|c|c|c|c|c|c|c|}
\hline \multirow[t]{2}{*}{ Generic Core $^{\mathrm{a}}$} & \multicolumn{7}{|c|}{ Symptom severity group ${ }^{\mathrm{b}}$ domain scores mean (SD) } & \multicolumn{5}{|c|}{ Differences between groups } \\
\hline & \multicolumn{2}{|l|}{$\begin{array}{l}\text { Mild (1) } \\
n=37\end{array}$} & \multicolumn{2}{|c|}{$\begin{array}{l}\text { Moderate }(2) \\
n=39\end{array}$} & \multicolumn{3}{|c|}{$\begin{array}{l}\text { Severe (3) } \\
n=12\end{array}$} & \multicolumn{3}{|c|}{ Groups $^{b, c}$} & \multicolumn{2}{|c|}{$\begin{array}{l}\text { One-way ANOVA }{ }^{\text {a }} \\
P \text {-values }{ }^{\mathrm{d}}\end{array}$} \\
\hline Total score & $89(13)$ & \multicolumn{3}{|c|}{$72(15)$} & \multicolumn{3}{|l|}{$51(9)$} & 1 & 2 & 3 & \multicolumn{2}{|c|}{$\begin{array}{l}1 \text { versus } 2, P<0.001^{* * *} \\
2 \text { versus } 3, P<0.001^{* * *} \\
1 \text { versus } 3, P<0.001^{* * *}\end{array}$} \\
\hline Physical health score & $88(16)$ & \multicolumn{3}{|c|}{$73(24)$} & \multicolumn{3}{|c|}{$42(15)$} & 1 & 2 & 3 & \multicolumn{2}{|c|}{$\begin{array}{l}1 \text { versus } 2, P=0.007^{* *} \\
2 \text { versus } 3, P<0.001^{* * *} \\
1 \text { versus } 3, P<0.001^{* * *}\end{array}$} \\
\hline Psychosocial functioning & $89(12)$ & \multicolumn{3}{|c|}{$71(13)$} & \multicolumn{3}{|c|}{$55(10)$} & 1 & 2 & 3 & \multicolumn{2}{|c|}{$\begin{array}{l}1 \text { versus } 2, P<0.001^{* * *} \\
2 \text { versus } 3, P=0.001^{* * *} \\
1 \text { versus } 3, P<0.001^{* * *}\end{array}$} \\
\hline Emotional functioning & $87(15)$ & \multicolumn{3}{|c|}{$65(15)$} & \multicolumn{3}{|c|}{$53(19)$} & 1 & 2 & 3 & \multicolumn{2}{|c|}{$\begin{array}{l}1 \text { versus } 2, P<0.001^{* * *} \\
2 \text { versus } 3, P=0.053 \\
1 \text { versus } 3, P<0.001^{* * *}\end{array}$} \\
\hline Social functioning & $93(12)$ & \multicolumn{3}{|c|}{$86(15)$} & \multicolumn{3}{|c|}{$74(15)$} & 1 & 2 & 3 & \multicolumn{2}{|c|}{$\begin{array}{l}1 \text { versus } 2, P=0.074 \\
2 \text { versus } 3, P=0.027^{*} \\
1 \text { versus } 3, P<0.001^{* * *}\end{array}$} \\
\hline Study/work functioning & 87 (17) & \multicolumn{3}{|c|}{$61(22)$} & \multicolumn{3}{|c|}{$38(15)$} & 1 & 2 & 3 & \multicolumn{2}{|c|}{$\begin{array}{l}1 \text { versus } 2, P<0.001^{* * *} \\
2 \text { versus } 3, P=0.001^{* * *} \\
1 \text { versus } 3, P<0.001^{* * *}\end{array}$} \\
\hline \multirow[t]{2}{*}{ Cancer Module } & \multirow{2}{*}{$\begin{array}{l}\text { Mild (1) } \\
n=37\end{array}$} & \multirow{2}{*}{\multicolumn{2}{|c|}{$\begin{array}{l}\text { Moderate (2) } \\
n=39\end{array}$}} & Severe (3) & & ferenc & $\operatorname{ces} \mathrm{b}$ & een & roups & & & \\
\hline & & & & $=12$ & & $u_{p s}^{b, c}$ & & $\begin{array}{l}\text { Mar } \\
P-\mathrm{v}\end{array}$ & $\begin{array}{l}\text { n-Wl } \\
\text { lues }\end{array}$ & hitney $^{\mathrm{f}}$ & & $\begin{array}{l}\mathrm{K}-\mathrm{W}^{\mathrm{g}} \\
P \text {-values }\end{array}$ \\
\hline Pain and hurt & $88(18)$ & $71(22)$ & & $0(23)$ & 1 & 2 & 3 & $\begin{array}{l}1 \mathrm{ve} \\
2 \mathrm{ve} \\
1 \mathrm{ve}\end{array}$ & $\begin{array}{l}\text { rsus } 2 \\
\text { rsus } 3 \\
\text { rsus } 3\end{array}$ & $\begin{array}{l}2, P<0 \\
3, P=0 \\
3, P<0\end{array}$ & $\begin{array}{l}.001 * * * \\
.014^{*} \\
.001 * * *\end{array}$ & $P<0.001$ \\
\hline Nausea & $95(11)$ & $84(16)$ & & $8(21)$ & 1 & 2 & 3 & $\begin{array}{l}1 \mathrm{ve} \\
2 \mathrm{ve} \\
1 \mathrm{ve}\end{array}$ & $\begin{array}{l}\text { rsus } 2 \\
\text { rsus } 3 \\
\text { rsus } 3\end{array}$ & $\begin{array}{l}2, P<0 \\
3, P<0 \\
3, P<0\end{array}$ & $\begin{array}{l}.001 * * * \\
.001 * * * \\
.001 * * *\end{array}$ & $P<0.001$ \\
\hline Procedural anxiety & $93(15)$ & $75(31)$ & & $6(38)$ & 1 & & 3 & $\begin{array}{l}1 \mathrm{ve} \\
2 \mathrm{ve} \\
1 \mathrm{ve}\end{array}$ & $\begin{array}{l}\text { rsus } 2 \\
\text { rsus } 3 \\
\text { rsus } 3\end{array}$ & $\begin{array}{l}2, P=0 \\
3, P=0 \\
3, P<0\end{array}$ & $\begin{array}{l}0.002^{* * *} \\
.098 \\
.001 * * *\end{array}$ & $P<0.001$ \\
\hline Treatment anxiety & $92(16)$ & $73(31)$ & & $5(32)$ & 1 & $\underline{2}$ & 3 & $\begin{array}{l}1 \mathrm{v} \\
2 \mathrm{ve} \\
1 \mathrm{ve}\end{array}$ & $\begin{array}{l}\text { rsus } 2 \\
\text { rsus } 3 \\
\text { rsus } 3\end{array}$ & $\begin{array}{l}2, P=\mathrm{c} \\
3, P=\mathrm{c} \\
3, P=\mathrm{c}\end{array}$ & $\begin{array}{l}0.001 * * * \\
0.442 \\
0.001 * * *\end{array}$ & $P<0.001$ \\
\hline Worry & $80(20)$ & $67(18)$ & & $7(26)$ & 1 & 2 & 3 & $\begin{array}{l}1 \mathrm{v} \\
2 \mathrm{ve} \\
1 \mathrm{ve}\end{array}$ & $\begin{array}{l}\text { rsus } 2 \\
\text { rsus } 3 \\
\text { rsus } 3\end{array}$ & $\begin{array}{l}2, P=0 \\
3, P=0 \\
3, P<0\end{array}$ & $\begin{array}{l}.001 * * * \\
.007 * * \\
.001 * * *\end{array}$ & $P<0.001$ \\
\hline Cognitive problems & $88(16)$ & $64(23)$ & & $4(28)$ & 1 & $\underline{2}$ & 3 & $\begin{array}{l}1 \mathrm{v} \\
2 \mathrm{ve} \\
1 \mathrm{v}\end{array}$ & $\begin{array}{l}\text { rsus } 2 \\
\text { rsus } 3 \\
\text { rsus } 3\end{array}$ & $\begin{array}{l}2, P<0 \\
3, P=0 \\
3, P=0\end{array}$ & $\begin{array}{l}.001 * * * \\
.163 \\
.001^{* * *}\end{array}$ & $P<0.001$ \\
\hline
\end{tabular}


Table 5 continued

\begin{tabular}{|c|c|c|c|c|c|c|c|}
\hline \multirow[t]{2}{*}{ Cancer Module ${ }^{\mathrm{e}}$} & \multirow{2}{*}{$\begin{array}{l}\text { Mild (1) } \\
n=37\end{array}$} & \multirow{2}{*}{$\begin{array}{l}\text { Moderate (2) } \\
n=39\end{array}$} & \multirow{2}{*}{$\begin{array}{l}\text { Severe (3) } \\
n=12\end{array}$} & \multicolumn{4}{|c|}{ Differences between groups } \\
\hline & & & & & $\mathrm{ups}^{\mathrm{b}, \mathrm{c}}$ & $\begin{array}{l}\text { Mann-Whitney }{ }^{\mathrm{f}} \\
P \text {-values }^{\mathrm{d}}\end{array}$ & $\begin{array}{l}\mathrm{K}-\mathrm{W}^{\mathrm{g}} \\
P \text {-values }\end{array}$ \\
\hline Perceived physical appearance & $84(19)$ & $63(27)$ & $68(28)$ & 1 & 23 & $\begin{array}{l}1 \text { versus } 2, P=0.001^{* * *} \\
2 \text { versus } 3, P=0.546 \\
1 \text { versus } 3, P=0.048^{*}\end{array}$ & $P=0.003$ \\
\hline Communication & $92(16)$ & $69(23)$ & $63(25)$ & 1 & 23 & $\begin{array}{l}1 \text { versus } 2, P<0.001^{* * * *} \\
2 \text { versus } 3, P=0.481 \\
1 \text { versus } 3, P<0.001^{* * *}\end{array}$ & $P<0.001$ \\
\hline
\end{tabular}

a GC scales, analysed using One-way ANOVA, pair-wise $P$-values calculated by Tukey's HSD Post Hoc Test

b Known groups, "Mild", "Moderate" and "Severe" were identified by AYA scores on the MSAS-PHYS scale

c The "Groups" column shows the level of significance between pairs of symptom groups e.g., for Emotional Functioning a weak difference between Moderate and Severe symptom groups, 2 and 3 is shown as "1 223 " $(P=0.053)$, while Cognitive Problems shows no significant difference between groups 2 and $3(P=0.163)$

d Significance levels: * indicates $P$-values $\leq 0.05$; ** indicates $P$-values $\leq 0.01$; and *** indicates $P$-values $\leq 0.001$

e CM scales did not meet normality requirements so non-parametric analyses were conducted

f The Mann-Whitney U-test was used to determine significance between pairs of groups within domains of CM

g The Kruskal-Wallis (K-W) non-parametric Test, used to decide significance between CM symptom groups

reported severe symptoms. Two-thirds (60/88) of the AYA patients were off-treatment (Table 2), and of these, $45 \%$ $(27 / 60)$ reported moderate to severe symptoms. A quarter of the people with severe symptoms were off-treatment at recruitment.

Table 3 (self-report) and Table 4 (proxy-report) show the means, standard deviations (SD), and internal consistency Cronbach's alpha $(\alpha)$, coefficients of the AYA modified Generic Core Scales and Cancer Module scores for the whole sample, and the percentage of scores at the ends of the scale range (floor and ceiling effects) for the three symptom-severity groups. Minimal missing responses on items of the AYA version of the Generic Core Scales and Cancer Module suggested that participants were willing and able to provide good quality data regarding AYA HRQOL. Cronbach's alpha values for scales of the Generic Core ranged from 0.81-0.95 (AYA) and 0.85-0.96 (proxy), and for the modified Cancer Module they were 0.75-0.90 (AYA) and 0.83-0.98 (Proxy).

Table 5 (self-report) and Table 6 (proxy-report) show that the gradient of the mean HRQOL scores across the symptom-severity groupings was as expected. Most pairwise comparisons were statistically significant (readily seen in the column marked "Groups"), demonstrating the ability of the scales to distinguish between these symptom groups.

Factor structures were consistent with those reported previously for the Generic Core (Table 7) and Cancer Module (Table 8), for both self-report and proxy-report. Proportions of variance accounted for in self-report and proxy-report were: Generic Core $74 \%$ and $75 \%$ explained by a five-factor solution; and Cancer Module $76 \%$ and $84 \%$ by a six-factor solution. Item factor loadings from Varni's original sample [15] are presented in Table 7 for comparison; these relate to version 4.0 administered in a sample aged 2-18 years. In our analyses, more of the variance was accounted for (74\% patient and 75\% proxy) than in Varni's original study in children (52\% and $62 \%$, respectively) [16].

Table 9 shows the correlations between the AYA modified Generic Core Scales and Cancer Module for AYA versus AYA (above the leading diagonal) and proxy versus proxy (below the diagonal), with AYA-proxy concordance shown in bold on the leading diagonal. Correlations among the scales of the Generic Core and the Cancer Module were generally in the moderate to large size range for both selfreport (i.e. AYA vs. AYA Generic Core: 0.53-0.95; Cancer Module: $0.23-0.65$ ) and proxy-report (i.e. Proxy vs. proxy $0.54-0.95$ and $0.30-0.75$ ).

The self/proxy correlations were as expected, generally in the medium to large size range $(r=0.56-0.85$ Generic Core and 0.36-0.67 Cancer Module). There was little systematic bias between AYA self-report and proxy (Fig. 1a, Generic Core Scales; Fig. 1b, Cancer Module). The only statistically significant difference was for the social functioning scale $(P=0.037)$, with proxies underestimating AYA HRQOL. Proxies also underestimated emotional function $(P=0.08)$ and psychosocial health summary score $(P=0.10)$. 
Table 6 Proxy-report by Symptom Severity Group using the AYA modified PedsQL Generic Core Scales and Cancer Module domain scores $(n=79)$

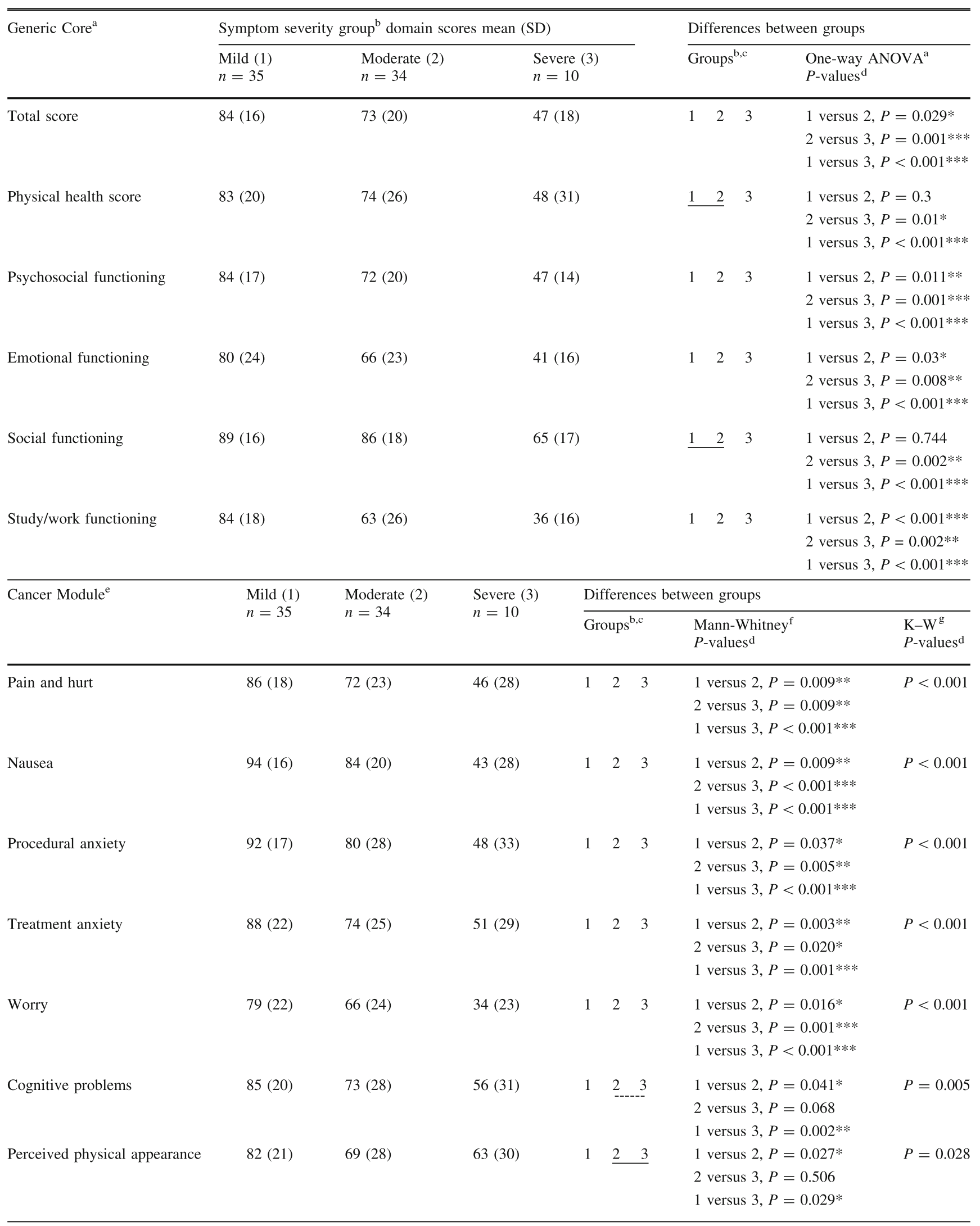


Table 6 continued

\begin{tabular}{|c|c|c|c|c|c|c|}
\hline \multirow[t]{2}{*}{ Cancer Module ${ }^{e}$} & \multirow{2}{*}{$\begin{array}{l}\text { Mild (1) } \\
n=35\end{array}$} & \multirow{2}{*}{$\begin{array}{l}\text { Moderate (2) } \\
n=34\end{array}$} & \multirow{2}{*}{$\begin{array}{l}\text { Severe (3) } \\
n=10\end{array}$} & \multicolumn{3}{|c|}{ Differences between groups } \\
\hline & & & & Groups $^{\mathrm{b}, \mathrm{c}}$ & $\begin{array}{l}\text { Mann-Whitney }{ }^{\mathrm{f}} \\
P \text {-values }^{\mathrm{d}}\end{array}$ & $\begin{array}{l}\mathrm{K}-\mathrm{W}^{\mathrm{g}} \\
P \text {-values } \mathrm{d}\end{array}$ \\
\hline Communication & $84(21)$ & $74(27)$ & $64(36)$ & $1 \quad 2 \quad 3$ & $\begin{array}{l}1 \text { versus } 2, P=0.075 \\
2 \text { versus } 3, P=0.439 \\
1 \text { versus } 3, P=0.097\end{array}$ & $P=0.10$ \\
\hline
\end{tabular}

a GC scales, analysed using One-way ANOVA, pair-wise $P$-values calculated by Tukey's HSD Post Hoc Test

b Known groups, "Mild", "Moderate" and "Severe" were identified by AYA scores on the MSAS-PHYS scale

c The "Groups" column shows the level of significance between pairs of symptom groups e.g., Proxies reported significant differences between symptom groups for Emotional Functioning at 5\% level i.e., "1 2 3", and no difference between Mild and Moderate symptom groups for Social functioning i.e., $12, P=0.744$

d Significance levels: * indicates $P$-values $\leq 0.05$; ** indicates $P$-values $\leq 0.01$; and *** indicates $P$-values $\leq 0.001$

e CM scales did not meet normality requirements so non-parametric analyses were conducted

f The Mann-Whitney U-test was used to determine significance between pairs of groups within domains of CM

g The Kruskal-Wallis (K-W) non-parametric Test, used to decide significance between CM symptom groups

Table 7 Factor structure $^{\mathrm{a}}$ of the AYA modified PedsQL Generic Core Scales for the self- and proxy-report from the Ewing sample and from Varni's original validation sample ${ }^{\mathrm{b}}$

\begin{tabular}{|c|c|c|c|c|c|c|c|c|c|c|c|c|c|c|c|c|c|c|c|}
\hline \multirow{3}{*}{\begin{tabular}{|l} 
Generic Core \\
Physical Functioning
\end{tabular}} & \multicolumn{10}{|c|}{ Self-Report $n=88$} & \multicolumn{9}{|c|}{ Proxy-Report $n=79$} \\
\hline & \multicolumn{2}{|l|}{1} & \multicolumn{2}{|c|}{2} & \multicolumn{2}{|c|}{3} & \multicolumn{2}{|c|}{4} & \multicolumn{2}{|l|}{5} & \multicolumn{2}{|c|}{1} & \multicolumn{2}{|c|}{2} & \multicolumn{2}{|c|}{3} & \multicolumn{2}{|c|}{4} & \multirow{2}{*}{5} \\
\hline & E1 & v2 & E2 & $\mathrm{V} 1$ & E3 & V5 & E4 & V3 & E5 & V4 & E1 & V1 & $\mathrm{E} 2$ & V3 & E3 & $\mathrm{V} 2$ & $\mathrm{E} 4$ & V5 & \\
\hline Hard to walk 1 & 0.84 & -0.72 & 0.09 & -0.05 & 0.16 & 0.05 & 0.13 & 0.00 & 0.24 & 0.12 & 0.90 & 0.83 & 0.13 & 0.04 & 0.09 & -0.11 & -0.03 & \begin{tabular}{|c||}
-0.02 \\
\end{tabular} & 0.02 \\
\hline Hard to run & 0.76 & -0.77 & -0.08 & 0.10 & 0.19 & 0.12 & 0.12 & -0.06 & 0.46 & 0.05 & 0.89 & 0.84 & 0.21 & 0.07 & -0.08 & -0.18 & 0.03 & -0.01 & .04 \\
\hline Hard to do sports a & \begin{tabular}{|l|}
0.76 \\
\end{tabular} & -0.78 & 0.05 & 0.09 & 0.23 & 0.06 & 0.12 & 0.01 & 0.39 & 0.00 & 0.88 & 0.80 & 0.11 & 0.10 & -0.01 & -0.09 & 0.09 & 0.01 & .06 \\
\hline Hard to lift so & \begin{tabular}{|l|}
0.69 \\
\end{tabular} & -0.46 & 0.22 & 0.14 & 0.16 & 0.05 & 0.29 & 0.06 & 0.27 & 0.16 & 0.81 & 0.75 & 0.23 & 0.10 & 0.15 & 0.03 & 0.18 & -0.08 & .04 \\
\hline Hard to take a bath/shower unaided & 0.78 & -0.57 & 0.27 & -0.06 & -0.12 & -0.24 & -0.04 & 0.01 & -0.02 & -0.14 & 0.63 & 0.72 & 0.02 & -0.11 & 0.48 & 0.22 & -0.14 & -0.02 & -0.08 \\
\hline Hardto do chores around house & \begin{tabular}{|l|}
0.88 \\
\end{tabular} & -0.65 & 0.08 & -0.04 & 0.11 & -0.21 & 0.11 & 0.01 & -0.05 & -0.11 & 0.70 & 0.74 & 0.19 & -0.02 & 0.26 & 0.19 & 0.25 & -0.02 & -0.07 \\
\hline Hurt or & 0.65 & -0.25 & 0.34 & 0.22 & 0.19 & 0.03 & 0.12 & 0.05 & 0.19 & 0.20 & 0.59 & 0.31 & 0.35 & 0.33 & 0.30 & -0.15 & 0.15 & $-0.02 \mid$ & 29 \\
\hline Low energy & 0.68 & -0.26 & 0.38 & 0.39 & 0.35 & $\mid-0.03$ & 0.10 & 0.03 & -0.08 & 0.14 & 0.57 & 0.27 & 0.54 & & 0.32 & -0.03 & 0.06 & $-0.04 \mid$ & \\
\hline \multicolumn{20}{|l|}{ Emotional Functioning } \\
\hline Feel afraid or scared & \begin{tabular}{|l|l|}
0.19 \\
\end{tabular} & -0.03 & 0.76 & 0.78 & 0.08 & 0.05 & 0.18 & 0.11 & 0.10 & -0.18 & 0.17 & 0.04 & 0.82 & 0.72 & 0.12 & 0.00 & 0.29 & 0.04 & -0.07 \\
\hline Feel sad o & 0.21 & 0.10 & 0.68 & 0.78 & 0.11 & -0.02 & 0.17 & 0.07 & 0.52 & 0.01 & 0.25 & -0.02 & 0.80 & 0.77 & 0.35 & 0.05 & 0.15 & 0.08 & -0.02 \\
\hline Feel a & 0.17 & 0.01 & 0.52 & 0.66 & 0.24 & -0.11 & -0.03 & -0.04 & 0.61 & -0.02 & 0.11 & -0.04 & 0.72 & 0.66 & 0.38 & 0.09 & 0.07 & 0.10 & -0.03 \\
\hline Trouble & 0.30 & -0.13 & 0.74 & 0.37 & 0.18 & -0.18 & 0.08 & 0.05 & -0.08 & 0.13 & 0.28 & 0.04 & 0.71 & 0.54 & 0.18 & 0.08 & 0.24 & -0.01 & $\mid$\begin{tabular}{||c}
0.16 \\
\end{tabular} \\
\hline Worry about what will $\mathrm{h}$ & \begin{tabular}{|l|l|}
0.09 \\
\end{tabular} & 0.00 & 0.82 & 0.71 & 0.16 & 0.02 & 0.21 & $\mid-0.07$ & 0.14 & 0.04 & 0.24 & \begin{tabular}{|c|}
-0.03 \\
\end{tabular} & 0.83 & 0.78 & 0.07 & 0.04 & 0.26 & $|-0.02|$ & -0.05 \\
\hline \multicolumn{20}{|l|}{ Social Functioning } \\
\hline Trouble getting along with peers & \begin{tabular}{|l|l|}
-0.02 \\
\end{tabular} & 0.04 & 0.32 & 0.01 & 0.21 & -0.18 & \begin{tabular}{|l|l|}
0.60 \\
\end{tabular} & 0.68 & 0.30 & -0.08 & 0.13 & 0.04 & 0.29 & \begin{tabular}{|l|l|}
0.09 \\
\end{tabular} & 0.33 & 0.25 & 0.62 & 0.60 & -0.16 \\
\hline Other youth not wanting to be frie & 0.13 & 0.02 & 0.15 & -0.04 & 0.15 & -0.05 & 0.84 & 0.81 & 0.05 & -0.11 & 0.05 & -0.04 & 0.38 & 0.06 & 0.07 & 0.02 & 0.82 & 0.84 & -0.02 \\
\hline Teased & \begin{tabular}{|l|}
0.19 \\
\end{tabular} & 0.10 & 0.10 & 0.09 & 0.08 & -0.01 & 0.83 & 0.75 & 0.06 & 0.05 & 0.15 & -0.06 & 0.09 & 0.10 & 0.18 & -0.10 & 0.83 & 0.81 & .08 \\
\hline Unable to do things peers do & 0.60 & -0.31 & 0.05 & \begin{tabular}{|l|l|}
0.07 \\
\end{tabular} & 0.10 & 0.17 & 0.33 & 0.42 & 0.59 & 0.18 & 0.72 & 0.48 & 0.20 & \begin{tabular}{|c|}
-0.08 \\
\end{tabular} & 0.36 & 0.02 & 0.28 & 0.41 & .13 \\
\hline Hard to keep up with peers & 0.45 & -0.35 & 0.12 & \begin{tabular}{|c|}
-0.03 \\
\end{tabular} & 0.17 & 0.21 & 0.33 & 0.42 & 0.67 & 0.24 & 0.71 & 0.55 & 0.23 & \begin{tabular}{|l|}
-0.13 \\
\end{tabular} & 0.32 & 0.15 & 0.26 & 0.37 & 0.12 \\
\hline \multicolumn{20}{|l|}{ Study/Work Functioning } \\
\hline Hard to concentrate class/at work & \begin{tabular}{|l|l|}
0.28 \\
\end{tabular} & -0.06 & 0.16 & 0.12 & 0.83 & \begin{tabular}{|c|}
-0.71 \\
\end{tabular} & \begin{tabular}{|l|l|}
0.19 \\
\end{tabular} & 0.08 & 0.18 & 0.04 & 0.26 & 0.03 & 0.31 & 0.09 & 0.76 & 0.81 & 0.29 & 0.06 & .01 \\
\hline Forget things & 0.04 & 0.00 & 0.19 & 0.21 & 0.86 & \begin{tabular}{|c|}
-0.52 \\
\end{tabular} & 0.21 & 0.09 & 0.05 & 0.14 & 0.10 & 0.03 & 0.31 & 0.13 & 0.68 & 0.73 & 0.38 & -0.03 & .08 \\
\hline Trouble keeping up with study/work & \begin{tabular}{|l|}
0.50 \\
\end{tabular} & -0.12 & 0.11 & -0.05 & 0.68 & \begin{tabular}{|c|}
-0.68 \\
\end{tabular} & 0.07 & 0.14 & 0.22 & 0.20 & 0.26 & 0.02 & 0.42 & 0.04 & 0.72 & 0.77 & 0.26 & 0.05 & 15 \\
\hline Miss class/work - not feeling well & 0.62 & 0.00 & 0.35 & 0.00 & 0.53 & -0.14 & 0.10 & -0.05 & 0.11 & 0.80 & 0.49 & -0.04 & 0.53 & -0.04 & 0.45 & 0.11 & 0.14 & -0.05 & 90 \\
\hline Miss class/work - Dr or hospital appt. & 0.66 & 0.06 & 0.30 & -0.03 & 0.37 & -0.07 & -0.02 & -0.01 & 0.17 & 0.85 & 0.60 & -0.03 & 0.41 & \begin{tabular}{|l|}
-0.02 \\
\end{tabular} & 0.41 & 0.07 & -0.05 & 0.07 & 0.86 \\
\hline$\%$ of Total Variance & $47 \%$ & & $10 \%$ & & $7 \%$ & & $6 \%$ & & $4 \%$ & & $51 \%$ & & $13 \%$ & & $6 \%$ & & $5 \%$ & & \\
\hline
\end{tabular}

${ }^{a}$ Item factor loadings from Principal Components Analysis with Varimax Rotation and an Eigenvalue cut-off at 1.0

b Ewing sample (as reported in this paper) is labelled E1-5; Varni's sample is labelled V1-5 (as reported in Varni (2001), where version 4.0 was administered in a sample aged $2-18$ years and parent-proxies 
Table 8 Factor structure ${ }^{\mathrm{a}}$ of the AYA modified PedsQL Cancer Module ${ }^{\mathrm{b}}$ for self-report and proxy-report

\begin{tabular}{|c|c|c|c|c|c|c|c|c|c|c|c|c|}
\hline \multirow{2}{*}{ Cancer Module } & \multicolumn{6}{|c|}{ Adolescents \& Young Adults } & \multicolumn{6}{|c|}{ Proxy } \\
\hline & 1 & 2 & 3 & 4 & 5 & 6 & 1 & 2 & 3 & 4 & 5 & 6 \\
\hline \multicolumn{13}{|l|}{ Pain \& Hurt } \\
\hline \multirow{2}{*}{$\begin{array}{l}\text { Aches in joints and/or muscles } \\
\text { Having a lot of pain }\end{array}$} & .143 & .314 & -.043 & .757 & -.025 & -.022 & -.174 & .652 & .108 & .422 & .160 & .057 \\
\hline & .201 & .484 & .022 & .671 & -.010 & .047 & .049 & .711 & .140 & .390 & .232 & .232 \\
\hline \multicolumn{13}{|l|}{ Nausea } \\
\hline \multirow{5}{*}{$\begin{array}{l}\text { Become nauseated during medical treatments } \\
\text { Food not tasting very good } \\
\text { Become nauseated while thinking about medical treatments } \\
\text { Feeling too nauseous to eat } \\
\text { Some foods and smells cause nausea }\end{array}$} & .140 & .755 & $\mid-.014$ & .280 & .283 & -.131 & .431 & .821 & .166 & .109 & .075 & -.080 \\
\hline & .058 & .825 & .180 & .227 & .065 & .059 & .220 & .809 & .341 & .019 & .072 & .029 \\
\hline & .199 & .602 & .243 & .231 & .447 & -.078 & .586 & .653 & .121 & .252 & .075 & .117 \\
\hline & .287 & .710 & .087 & .306 & .088 & .082 & .366 & .788 & .204 & .090 & .187 & .047 \\
\hline & .333 & .726 & .046 & -.086 & .071 & -.005 & .258 & .841 & .212 & .077 & -.036 & .132 \\
\hline \multicolumn{13}{|l|}{ Procedural Anxiety } \\
\hline \multirow{4}{*}{$\begin{array}{l}\text { Problems with Needle Sticks (injections, blood tests, IV) Hurt } \\
\text { Get anxious about Blood Tests } \\
\text { Get anxious about Needle Sticks (i.e. injections, BT and IV's) } \\
\text { Treatment Anxiety }\end{array}$} & .227 & .175 & .161 & .148 & .807 & .100 & .847 & .284 & .149 & .140 & .067 & .141 \\
\hline & .058 & .294 & .506 & -.116 & .658 & .205 & .880 & .129 & .207 & .149 & .131 & .176 \\
\hline & .155 & .206 & .431 & .030 & .762 & .077 & .880 & .249 & .191 & .124 & .075 & .133 \\
\hline & & & & & & & & & & & & \\
\hline \multirow{4}{*}{$\begin{array}{l}\text { Get anxious while waiting to see the Doctor } \\
\text { Get anxious about going to the doctor } \\
\text { Get anxious about going to the hospital } \\
\text { Worry }\end{array}$} & .273 & .007 & .841 & .095 & .195 & .010 & .672 & .157 & .119 & .500 & .271 & .136 \\
\hline & .250 & -.008 & .828 & .007 & .306 & .033 & .707 & .134 & .147 & .469 & .289 & .062 \\
\hline & .305 & .036 & .702 & .215 & .410 & .034 & .684 & .317 & .232 & .409 & .204 & .077 \\
\hline & \\
\hline \multirow{3}{*}{$\begin{array}{l}\text { Worry about side effects from the medical treatments } \\
\text { Worry about whether the medical treatments are working } \\
\text { Worry that the cancer will reoccur }\end{array}$} & -.086 & .454 & .207 & .557 & .255 & .274 & .454 & .360 & .070 & .653 & .139 & .162 \\
\hline & .109 & .198 & .534 & .547 & .114 & .173 & .344 & .283 & .200 & .771 & .093 & .117 \\
\hline & -.061 & .246 & .754 & -.028 & \begin{tabular}{l|l|}
.035 \\
\end{tabular} & .276 & .383 & .099 & .225 & .741 & -.015 & .087 \\
\hline \multicolumn{13}{|l|}{ Cognitive Problems } \\
\hline \multirow{6}{*}{$\begin{array}{l}\text { Difficulty figuring out what to do when som } \\
\text { Trouble solving maths problems } \\
\text { Trouble writing study papers or reports } \\
\text { Difficulty paying attention to things } \\
\text { Difficulty remembering what he/she read. } \\
\text { Perceived Physical Appearance }\end{array}$} & .592 & .209 & .319 & .406 & .107 & .054 & .269 & .235 & .593 & .269 & .332 & .369 \\
\hline & .791 & .149 & .123 & -.033 & .202 & .067 & .123 & .136 & .822 & .108 & .212 & .152 \\
\hline & .834 & .219 & .192 & .044 & -.021 & .087 & .139 & .230 & .872 & .102 & .225 & .066 \\
\hline & .762 & .396 & .056 & .125 & .054 & .219 & .169 & .267 & .799 & .156 & .290 & .129 \\
\hline & .831 & .260 & .190 & .006 & .132 & .016 & .179 & .244 & .800 & .116 & .191 & .132 \\
\hline & & & & & & & & & & & & \\
\hline \multirow{3}{*}{$\begin{array}{l}\text { Feeling that he/she is not good looking } \\
\text { Not liking other people to see his/her sc: } \\
\text { Being embarrassed about others seeing } 1\end{array}$} & .163 & .279 & .440 & -.183 & -.229 & .574 & .306 & .099 & .511 & .160 & -.180 & .605 \\
\hline & .074 & -.124 & -.015 & .220 & .254 & .799 & .104 & .040 & .084 & .102 & .279 & .845 \\
\hline & .116 & .012 & .203 & .018 & .054 & .894 & .162 & .116 & .234 & .083 & .185 & .851 \\
\hline \multicolumn{13}{|l|}{ Communication } \\
\hline Difficulty telling the doctors and nurses how he/she feels & .598 & .069 & .238 & .459 & .162 & -.098 & .180 & .251 & .440 & .139 & .706 & .259 \\
\hline \multirow{3}{*}{$\begin{array}{l}\text { Difficulty asking the doctors and nurses questions } \\
\text { Difficulty explaining his/her illness to other people } \\
\% \text { of total variance (initial Eigenvalue) }\end{array}$} & .655 & -.117 & .051 & .519 & .046 & -.020 & .215 & .072 & .417 & .122 & .748 & .205 \\
\hline & .539 & $\begin{array}{l}.049 \\
\end{array}$ & -.101 & .461 & .211 & .244 & .225 & .171 & .402 & .060 & .768 & .159 \\
\hline & $37 \%$ & $12 \%$ & $9 \%$ & $7 \%$ & $6 \%$ & $5 \%$ & $51 \%$ & $11 \%$ & $9 \%$ & $5 \%$ & $4 \%$ & $4 \%$ \\
\hline
\end{tabular}

a Item factor loadings from Principal Components Analysis with Varimax Rotation and an Eigenvalue cut-off at 1.0

b Varni et al. determined the eight domains through interviews and focus groups

\section{Discussion}

This study presents the measurement properties for new adolescent and young adult (AYA) forms of the PedsQL Generic Core Scales and PedsQL Cancer Module [14], with patient self-report and parallel versions for their nominated proxy in the context of cancer or a blood disorder. Our results support the reliability and validity of the AYA forms, both in self report and proxy versions, with reasonable agreement and correlation between AYA and proxies. Factor structures generally consistent with those of the adolescent forms confirmed construct validity. Cronbach's alpha were all greater than 0.81 , confirming internal constancy reliability. Inter-scale correlations were as hypothesized, confirming discriminant validity. Statistically significant differences between groups with mild, moderate and severe symptoms confirmed clinical validity. The scales of these instruments demonstrated minimal ceiling effects and no floor effects in this patient group. These results demonstrate that these new AYA forms are suitable for clinical research.

We have demonstrated that the new AYA forms of the PedQL Generic Core Scales and Cancer Module can differentiate the expected HRQOL gradient across mild, moderate, and severe symptom groups. As hypothesised, HRQOL was inversely related to symptom level, consistent with the conceptualisations of disease-specific symptoms as causal indicators of HRQOL [3, pp 46, 66]. Our results corroborate Varni et al. for the acute version self-report used in children on-treatment for more than 12 months versus healthy children, where the Generic Core Scales showed significant differences across all 
Table 9 AYA Modified PedsQL Generic Core Scales and Cancer Module correlations between AYA (above the leading diagonal), between proxies (below the diagonal), and AYA-proxy concurrence on the diagonal

\begin{tabular}{|c|c|c|c|c|c|c|c|c|c|c|c|c|c|c|c|}
\hline & & \multicolumn{14}{|c|}{ Adolescent and young adult (AYA) } \\
\hline & & TOT & Phys & Psych & Em & Soc & $\begin{array}{l}\text { S/ } \\
\text { Wk }\end{array}$ & $\begin{array}{l}P \text { and } \\
H\end{array}$ & $\mathrm{~N}$ & PA & TA & W & $\mathrm{CP}$ & A & Com \\
\hline \multirow[t]{14}{*}{ Proxy } & Total score & 0.811 & 0.918 & 0.954 & 0.751 & 0.788 & 0.869 & 0.72 & 0.709 & 0.302 & 0.318 & 0.581 & 0.586 & $0.252 *$ & 0.514 \\
\hline & Physical health & 0.884 & 0.852 & 0.755 & 0.531 & 0.663 & 0.716 & 0.669 & 0.626 & $0.213^{*}$ & ns & 0.461 & 0.376 & ns & 0.362 \\
\hline & Psychosocial health & 0.951 & 0.695 & 0.738 & 0.835 & 0.796 & 0.891 & 0.68 & 0.694 & 0.337 & 0.404 & 0.608 & 0.682 & 0.33 & 0.573 \\
\hline & Emotional functioning & 0.818 & 0.542 & 0.897 & 0.563 & 0.544 & 0.576 & 0.537 & 0.476 & 0.373 & 0.448 & 0.602 & 0.492 & 0.478 & 0.415 \\
\hline & Social functioning & 0.85 & 0.677 & 0.858 & 0.651 & 0.617 & 0.589 & 0.537 & 0.521 & $\mathrm{~ns}$ & ns & 0.493 & 0.417 & ns & 0.438 \\
\hline & Study/work functioning & 0.888 & 0.664 & 0.925 & 0.724 & 0.726 & 0.809 & 0.633 & 0.72 & 0.336 & 0.346 & 0.461 & 0.744 & ns & 0.573 \\
\hline & Pain and hurt & 0.801 & 0.724 & 0.751 & 0.681 & 0.608 & 0.713 & 0.541 & 0.534 & $\mathrm{~ns}$ & ns & 0.442 & 0.382 & ns & 0.486 \\
\hline & Nausea & 0.682 & 0.546 & 0.686 & 0.569 & 0.591 & 0.677 & 0.661 & 0.668 & 0.465 & 0.345 & 0.513 & 0.51 & ns & 0.37 \\
\hline & Procedural anxiety & 0.387 & ns & 0.478 & 0.506 & $0.276^{*}$ & 0.460 & 0.304 & 0.602 & 0.591 & 0.616 & 0.525 & 0.411 & 0.294 & 0.294 \\
\hline & Treatment anxiety & 0.489 & $0.282 *$ & 0.564 & 0.611 & 0.397 & 0.481 & 0.405 & 0.607 & 0.752 & 0.482 & 0.601 & 0.478 & 0.321 & 0.391 \\
\hline & Worry & 0.577 & 0.419 & 0.609 & 0.715 & 0.389 & 0.494 & 0.526 & 0.576 & 0.633 & 0.743 & 0.359 & 0.351 & 0.421 & 0.302 \\
\hline & Cognitive problems & 0.664 & 0.372 & 0.773 & 0.661 & 0.622 & 0.772 & 0.463 & 0.525 & 0.468 & 0.502 & 0.461 & 0.646 & $0.262 *$ & 0.652 \\
\hline & $\begin{array}{l}\text { Perceived physical } \\
\text { appearance }\end{array}$ & 0.463 & 0.295 & 0.515 & 0.491 & 0.400 & 0.477 & 0.307 & 0.332 & 0.427 & 0.436 & 0.415 & 0.541 & 0.643 & $0.225 *$ \\
\hline & Communication & 0.481 & $0.226^{*}$ & 0.590 & 0.522 & 0.463 & 0.580 & 0.404 & 0.44 & 0.435 & 0.517 & 0.421 & 0.731 & 0.509 & 0.601 \\
\hline
\end{tabular}

Pearson's correlation coefficients

All correlations were significant at the 0.01 level (two-tailed) unless indicated with an asterisk *

Interpretation: $r \geq 0.5$ large effect, $0.3 \leq r<0.5$ medium effect, $0.1 \leq r<0.3$ small effect [29]

Not significant $=\mathrm{ns}$. AYA sample $n=88$; Proxy $n=79$

Bolded numbers indicate: Total score versus Cancer Module for both AYA versus AYA and proxy versus proxy; and AYA-proxy concurrence on the leading diagonal

Fig. 1 a Mean differences in the AYA modified PedsQL Generic Core Scales between adolescent and young adult (AYA) self-report and proxyreport (AYA minus proxy*) with $95 \%$ confidence intervals. *Positive differences indicate proxies tended to underestimate AYA HRQOL. b Mean differences in the AYA modified PedsQL Cancer Module between adolescent and young adult (AYA) self-report and proxy-report (AYA minus proxy*) with $95 \%$ confidence intervals. *Positive differences indicate proxies tended to underestimate AYA HRQOL, while negative differences indicate proxies tended to overestimate AYA HRQOL
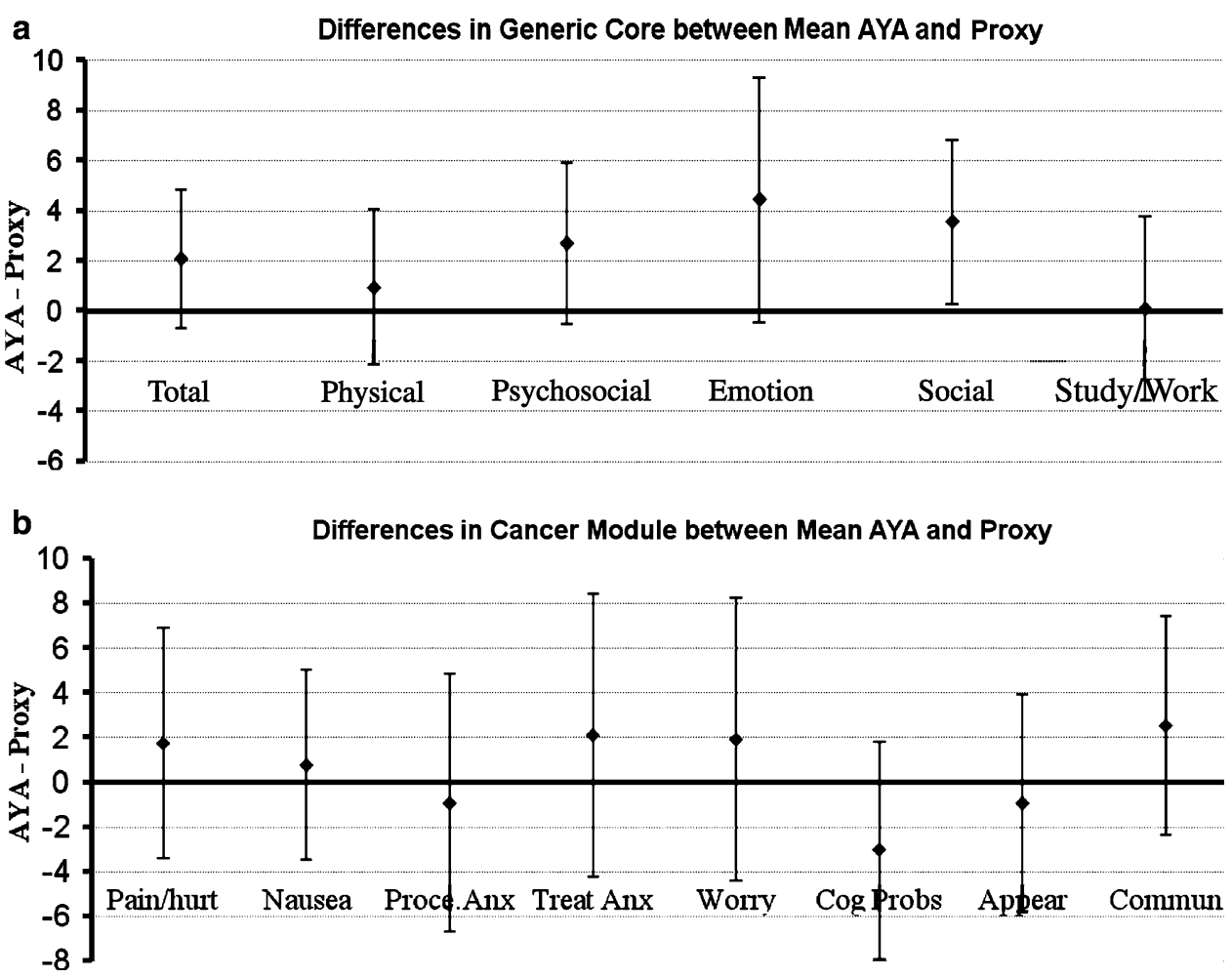
domains, while the Cancer Module showed a significant difference in three domains only (nausea, treatment anxiety and worry) [17] between on and off-treatment for more than 12 months.

The high Cronbach alpha values we report for the Generic Core Total Score (both self and proxy-report); make it suitable as a summary score of HRQOL outcome for use in clinical research [28]. For the Generic Core Scales, our AYA data demonstrated greater internal consistency than that reported by Varni et al. (0.70-0.92).

The factor structures in our data for both the Generic Core Scales and the Cancer Module Scales were generally consistent with those reported previously for the adolescent forms [14-16, 20]. Varni et al. determined the eight domains of the Cancer Module through interviews and focus groups [14]. While our AYA data suggests a better fit with a seven-factor solution (combining worry and treatment anxiety) and our proxy data suggest a sixfactor solution (combining treatment with procedural anxiety, and pain and hurt with nausea), we recommend scoring the AYA PedQL instruments according to Varni's standard scoring algorithm, as for other PedQL forms, to enable comparison across age groups and studies.

The patterns of correlations we found between the Generic Core Scales and Cancer Module Scales are consistent with the conceptualizations of disease-specific symptoms as causal indicators of HRQOL [3]. Despite the high statistical correlation, these domains are conceptually distinct, and as such provide useful insights in to the impact of symptoms on HRQOL and function. For example, the high correlations for the pain and nausea scales (Cancer Module) with all domains of the Generic Core highlight the impact pain has on other aspects of HRQOL.

The moderate to strong correlations between self-report and proxy-report is consistent with current literature [3, 14]. Although patient self-report is the standard for measuring HRQOL, the proxy's perception, particularly in the younger 16-19 age-group, may be an influential factor in health care utilisation, and must be used if the patient is unable or unwilling to complete the HRQOL assessment. Potential bias must also be considered. Reassuringly, our results show that there was little systematical bias in the proxy reports, although proxies did slightly underestimate the social and emotional functioning of AYA. Documenting the size and direction of this bias informs future use of proxy ratings on these scales where AYA data are not available, for whatever reason.

At the time of the study's commencement, the adolescent forms of these instruments were considered by our research team (a group of 24 medical specialists, nurses, psychologists, and researchers working with AYA at the three recruitment hospitals and collaborating universities) to be the most appropriate generic and cancer-specific HRQOL measurement tools for modification for the AYA target group, because they included role functioning items appropriate to this age range, they had previously been shown to be feasible, reliable, and valid in paediatric populations, and they were brief.

The validation and testing of these new AYA forms reported here has some limitations. Each dyad was assessed at only one time point, so the test-retest reliability and responsiveness were not determined. Information on nonparticipants was limited so we could not fully assess the generalisability of our results. The data are Australian, but are likely to generalise culturally similar countries such as New Zealand, the United Kingdom, USA, Canada and Europe. Wider field-testing of these forms would be valuable.

For some participants, much time may have passed since they were diagnosed with their illness and completed treatment. However, we did not record date of diagnosis. This may not be a limitation, because although two-thirds of our AYA sample were off-treatment, almost half of those people were still experiencing moderate to severe symptoms. Further, over half of our sample $(51 / 88=58 \%)$ reported moderate or severe symptoms, and a quarter of the people with severe symptoms were off-treatment at recruitment. This suggests that, from the patient's perspective, symptomatology may be more relevant than whether the patient is on or off-treatment.

This paper focuses on the provision of appropriate instruments for the collection of valid outcomes data for AYA people with cancer and blood disorders-a small but vital part in the quest for better health outcomes in this population. These new AYA forms of the PedsQL Generic Core Scales and the PedsQL Cancer Module have demonstrated the required reliability and validity for use as outcome measures in clinical trials, clinical practice, and future health research into AYAs. We note that they remain under the copyright of Professor James Varni's instruments (held by the MAPI Research Institute, France), and require author permission to use and may have licensing costs attached. We recommend that they be used in conjunction with valid measures of sexual health and fertility issues which are of concern to this age group.

Acknowledgments We are indebted to the participants for their time and effort and to their managing clinicians, the nurses, psychologists and researchers for their interest and co-operation. This research was funded in part by an Equity Completion Grant from the University of Technology, Sydney.

Open Access This article is distributed under the terms of the Creative Commons Attribution Noncommercial License which permits any noncommercial use, distribution, and reproduction in any medium, provided the original author(s) and source are credited. 


\section{References}

1. Adolescent and Young Adult Oncology Progress Review Group. (2006). Closing the gap: Research and care imperatives for adolescents and young adults with cancer. Department of Health and Human Services, National Institutes of Health, National Cancer Institute, and the LIVESTRONG ${ }^{\mathrm{TM}}$ Young Adult Alliance.

2. Hawkins, M. M. (2004). Long-term survivors of childhood cancers: What knowledge have we gained? Nature Clinical Practice Oncology, 1(1), 26-31. doi:10.1038/ncponc0020.

3. Fayers, P. M., \& Machin, D. (2000). Quality of life: Assessment, analysis and interpretation. West Sussex, England: Wiley.

4. National Institute for Health and Clinical Excellence. (2005). In: National Collaborating Centre for Cancer (Ed.), Improving outcomes in children and young people with cancer. The evidence review (136 pp). National Health Service, London.

5. Bleyer, W. A. (2001). The impact of cancer on adolescents and young adults: Epidemiology, diagnosis, treatment, survival, and importance of clinical trials. Medical and Pediatric Oncology, 37, 1-11. doi:10.1002/mpo.1154.

6. Bleyer, W. A. (2002). Cancer in older adolescents and young adults: Epidemiology, diagnosis, treatment, survival, and importance of clinical trials. Medical and Pediatric Oncology, 38(1), 1-10. doi:10.1002/mpo.1257.

7. Williams, G. (2006). Cancer among New Zealand adolescents and young people 1988-2002: An occasional paper. Ministry of Health, Wellington.

8. Pentheroudakis, G., \& Pavlidis, N. (2005). Juvenile cancer: Improving care for adolescents and young adults within the frame of medical oncology. Annals of Oncology, 16(2), 181-188. doi: 10.1093/annonc/mdi036.

9. Osoba, D. (1999). Interpreting the meaningfulness of changes in health-related quality of life scores: Lessons from studies in adults. International Journal of Cancer, 83(Suppl 12), 132-137. doi:10.1002/(SICI)1097-0215(1999)83:12+<132::AID-IJC23>3.0. $\mathrm{CO} ; 2-4$

10. Cella, D. F., Tulsky, D. S., Gray, G., et al. (1993). The functional assessment of cancer therapy scale: Development and validation of the general measure. Journal of Clinical Oncology, 11, 570-579.

11. Olsson, C. A., Sawyer, S. M., \& Boyce, M. (2000). What are the special needs of chronically ill young people? Australian Family Physician, 29(4), 299-300.

12. Bleyer, W. A. (2002). Older adolescents with cancer in North America deficits in outcome and research. Pediatric Clinics of North America, 49(5), 1027-1042. doi:10.1016/S0031-3955(02) 00035-4.

13. Mitchell, A. E., Scarcella, D. L., Rigutto, G. L., et al. (2004). Cancer in adolescents and young adults: Treatment and outcome in victoria. The Medical Journal of Australia, 180(2), 59-62.

14. Varni, J. W., Burwinkle, T. M., Katz, E. R., et al. (2002). The PedsQL in pediatric cancer: Reliability and validity of the pediatric quality of life inventory generic core scales, multidimensional fatigue scale, and cancer module. Cancer, 94(7), 2090-2106. doi: 10.1002/cncr.10428
15. Varni, J. W., Seid, M., \& Kurtin, P. S. (2001). The PedsQL 4.0: Reliability and validity of the pediatric quality of life inventory version 4.0 generic core scales in healthy and patient populations. Medical Care, 39, 800-812. doi:10.1097/00005650-20010800000006.

16. Varni, J. W., Seid, M., \& Rode, C. A. (1999). The PedsQL: Measurement model for the pediatric quality of life inventory. Medical Care, 37, 126-139. doi:10.1097/00005650-19990200000003.

17. Varni, J. W., Burwinkle, T. M., \& Katz, E. R. (2004). The PedsQL in pediatric cancer pain. A prospective longitudinal analysis of pain and emotional distress. Journal of Developmental and Behavioral Pediatrics, 25, 239-246. doi:10.1097/00004703200408000-00003.

18. Varni, J., Burwinkle, T., Jacobs, J., et al. (2003). The PedsQL in type 1 and type 2 diabetes: Reliability and validity of the pediatric quality of life inventory generic core scales and type 1 diabetes module. Diabetes Care, 26(3), 631-637. doi:10.2337/ diacare.26.3.631.

19. Uzark, K., Jones, K., Burwinkle, T. M., et al. (2003). The pediatric quality of life inventory in children with heart disease. Progress in Pediatric Cardiology, 18(2), 141-149. doi:10.1016/ S1058-9813(03)00087-0.

20. Varni, J. W., Seid, M., Knight, T. S., et al. (2002). The PedsQL 4.0 generic core scales: Sensitivity, responsiveness, and impact on clinical decision-making. Journal of Behavioral Medicine, 25, 175-193. doi:10.1023/A:1014836921812.

21. Osoba, D., \& King, M. (2005). Meaningful differences. In P. M. Fayers \& R. Hays (Eds.), Assessing quality of life in clinical trials (2nd ed., pp. 243-257). Oxford: Oxford University Press.

22. Collins, J., Devine, T. D., Dick, G. S., et al. (2002). The measurement of symptoms in young children with cancer: The validation of the memorial symptom assessment scale in children aged 7-12. Journal of Pain and Symptom Management, 23(1), 10-16. doi:10.1016/S0885-3924(01)00375-X.

23. Collins, J. J., Byrnes, M. E., Dunkel, I. J., et al. (2000). The measurement of symptoms in children with cancer. Journal of Pain and Symptom Management, 19(5), 363-377. doi:10.1016/ S0885-3924(00)00127-5.

24. Fairclough, D. L., \& Cella, D. F. (1996). Functional assessment of cancer therapy (fact-b): Non-response to individual questions. Quality of Life Research, 5(3), 321-329. doi:10.1007/BF0043 3916.

25. Fayers, P. M., Aaronson, N. K., Bjordal, K., et al. (1999). EORTC QLQ-C30 scoring manual, 2nd edn. EORTC Data Centre, Brussels, Belgium.

26. Ware, J. E., Snow, K. K., Kosinski, M., et al. (1993). Sf-36 health survey manual and interpretation guide. Boston, MA: New England Medical Center, The Health Institute.

27. Cronbach, L. (1951). Coefficient alpha and the internal structure of tests. Psychometrika, 16, 297-334. doi:10.1007/BF02310555.

28. Nunnally, J. C., \& Bernstein, I. H. (1994). Psychometric theory (3rd ed.). New York: McGraw-Hill

29. Cohen, J. (1988). Statistical power analysis for the behavioral sciences (2nd ed.). Hillsdale, NJ: Lawrence Earlbaum Associates. 